\title{
INQUERITO SORO-EPIDEMIOLÓGICO ANTILISTÉRIA EM UBERABA, MG
}

\author{
José Tavares-Neto, Guilherme Ferreira de Oliveira, \\ Abelardo Couto-Júnior, Jarbas Andrade e Ernesto Hofer
}

\begin{abstract}
Em 17. $1 \%$ dos 445 individuos pesaluisados foram onsenados anticompos contra at

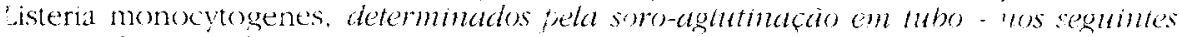

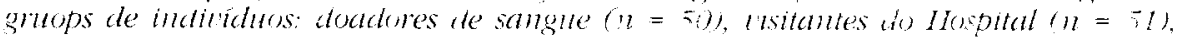

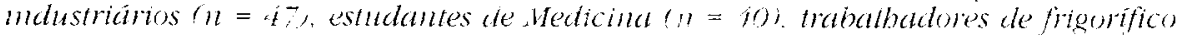

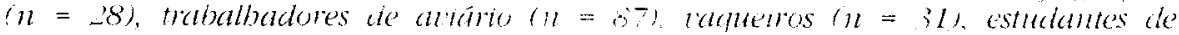
Agrotécilica $n=00)$ e trabaibadores da impeza pablica $(n=51)$. 0 simotitos $21 / 2 a$ fot

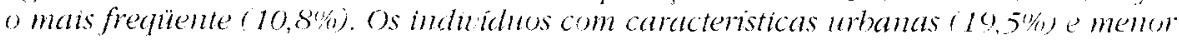

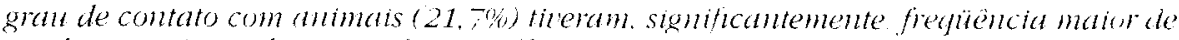

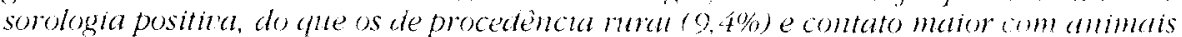
$(13,2 \%)$. Coeventemente, os indiabluos amostrados com ocupaçes mais especializadas

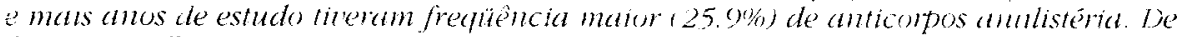
forma semelbante ao obseriado nos paises desenuoludos. onate a listeriose e problema de satide nas áreas arbanas.
\end{abstract}

Palabras-chates: Anticonpos antilistéria, Lenantamento. Listerna monocytogetnes. Sorro-epidemiologia

A Listeria monocytogenes tem distribuçao cosmopolita, acometendo também mamíferos e aves', isolada do solo e dos vegetais comestiveis'. Assim, a listeriose não é considerada uma zoonose clássica, mas uma anfixenose, com ciclo de transmissâo direta".

No homem, a $L$. monocylogenes provoca quadro dínico polimorfico, principalmente nos individuos imunosuprimidos é nos recémnascidos As apresentacoes clínicas mais comuns são quadros de meningoencetalite, septicemia e abortamento ${ }^{-}$

A listeriose é mais comum nos paises de clima temperado e nas areas urbanas. Talvez, em decorrência do agente etiológico ser mais freqüentemente isolado dios produtos animais industrializados ou dos alimentos comercializados $^{28}$. No Brasil, os casos clínicos são esporádicos". e tem poucos estudos soroepidemiológicos, principalmente, em indivíduos mais expostos aos anmais domésticos ou de interesse econômico como aos seus produtost.

Apesar da limitacáo do estudo soroepidemiológico devido as reacoes sorológicas

Faculdade de Medicina da Lniversidade Federal da Bahia, Salvador, BA; Faculdade de Medicina do Triângulo Mineiro, uberaba, MG e Fundação Oswaldo Cruz, Rio de Janeiro, RJ. Endereco para correspondência: José Tavares-Neto. R. Marques de Caravelas 262/101, 40240-140 Salvador, BA. Recebido para publicação em 22/06/94. cruzadas" esta análise evidencia as infeccoes passadas. Considerando as influencias exercidas cobre a populaçao através, inclusive, das atividades agropecuárias. Na região do Triangulo Mineiro, com economia fundamentada na agroindústria, procuroul-se verificar a frequêencia de portadores de anticorpos antilisteria en diferentes segmentos da populaçao. aparentemente sadia.

\section{MÁTERIAL E MÉTODOS}

Os individuos amostrados foram selecionados aleatoriamente. Assim, os doadores de sangue e as visitas dos pacientes do Hospital-Escola, da Faculdade de Medicina do Triangulo Mineiro. Ilberaba, foram incluídos com o devido consentimento, $\mathrm{cm}$ determinados dias da semana de junho de 1988. Os estudantes da Escola Federal de Agrotécnica. funcionários da indústria Fosfértil e os acadêmicos de Medicina (70 semestre de 1988) foram selecionados através de sorteios efetuados em abril. julho e agosto de 1988. respectivamente. De modo semelhante. os arabalhadores do trigorifico e de três aviários foram pesquisados em setembro e outubronovembro de 1988 . As amostras sanguíneas dos trabalhadores da limpeza pública foram coletados em janeiro-fevereiro de 1989, fornecidas espontaneamente, no local de trabalho. As amostras dos vaqueiros, de 
diferentes propriedades, também voluntários, foram coletados no periodo de fevereiromarço de 1989.

Um questionário foi aplicado nas pessoas amostradas, neste estudo, com respostas précodificadas e referentes aos: dados de identificação (sexo, idade e grupo racial), a ocupação atual classificada segundo o nível da especialização formal, local da residência, procedência, anos de estudo, renda familiar e grau de contato com animais ou produtos derivados. Este grau de contato foi estimado fazendo o somatório dos escores (dispostos em ordem crescente) das questoes, com respostas fechadas, associadas: ao trabalho com animais (pastoreio, ordenha, inseminaçào artificial), abate de animais, produção ou manipulacão industrial ou caseira de produtos animais, consumo de carnes, derivados e leite nào-pasteurizado, criação de animais de estimaça e práticas de lazer com animais. $O$ grau de contato foi classificado em maior e menor, os somatórios inferiores à mediana foram considerados menores.

De cada pessoa amostrada, foi coletado $10 \mathrm{ml}$ de sangue sem anticoagulante, e após separaça do soro, este era estocado a $-20^{\circ} \mathrm{C}$. O teste imunológico usado foi a soroaglutinaça em tubo', com antígenos somaticos dos sorotipos $L 1 / 2 a$ e L L b sendo a análise efetuada no Departamento de Bacteriologia da Fundação Oswaldo Cruz, Rio de Janeiro. O título foi considerado positivo quando igual ou maior a $1 / 80$.

\section{RESULTADOS}

O estudo foi realizado em 445 espécimes séricos, com freqüência de $17,1 \%(\mathrm{n}=76)$ de portadores de anticorpos antilistéria.

Na Tabela 1, o resultado da sorologia foi associada a cada grupo estudado, levando-se em consideração o total de soro-positivos para um sorotipo ou ambos sorotipos pesquisados. Entre os constituintes do grupo I a freqüência $(25,0 \%)$ dos soro-reagentes foi significantemente maior $\left(x^{2}=14,42\right.$ $p<0,00001)$, em comparação aos do grupo II (11,3\%). Os membros de cada grupo apresentaram freqüência de positividade muito semelhante $(p>0,30)$, quando comparados entre si. No entanto, os do grupo II, trabalhadores de aviário (5,7\%) e estudantes de Agrotécnica $(20,0 \%)$, revelaram níveis de frequiência de soro-reagentes estatisticamente diferentes entre si $\left(x^{2}=7,05 p<0,001\right)$. Por sua vez, os trabalhadores de aviário náo se diferenciaram dos demais elementos do grupo II, confrontados dois a dois $(p>0,10)$ - bem como os estudantes da escola Agrotécnica $(\mathrm{p}>0,20)$.

Outro aspecto retratado na Tabela 1, referese à freqüencia dos reagentes com o sorotipo L1/2a $(10,8 \%)$ e L $4 b(7,9 \%)$, em cada grupo. Em 7 indivícluos, os anticorpos antilistéria foram detectados para ambos sorotipos.

Na Tabela 2, as variáveis pesquisadas foram associadas ao resultado sorológico no conjunto dos indivíduos. Os indivíduos do

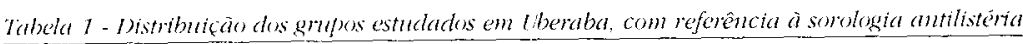

\begin{tabular}{|c|c|c|c|c|}
\hline \multirow{3}{*}{ Grilpo) } & \multirow[b]{3}{*}{$n$} & \multicolumn{3}{|c|}{ n positivos $(\%)$} \\
\hline & & \multirow[b]{2}{*}{ total ${ }^{*}$} & \multicolumn{2}{|c|}{ sorotipos } \\
\hline & & & $\mathrm{L} 1 / 2 \mathrm{a}$ & L4h \\
\hline $\bar{I}$ & 188 & $47(25,0)$ & $29(15,4)$ & $24(12,8)$ \\
\hline Dondores de sangue & 50 & $15(30.0)$ & $7(14.0)$ & $10(20.0)$ \\
\hline Visitas do hospital & 51 & $11(21,6)$ & $7(13.7)$ & $6(11.8\}$ \\
\hline Indesstriction & 47 & $12(25.5)$ & $8(17,0)$ & $4(8.5)$ \\
\hline Fstudinntes de medicina & 40 & $9(22.5)$ & $7(17.5)$ & $4(10,0)$ \\
\hline II & 257 & $29(11.3)$ & $19(7.4)$ & $11(4.2)$ \\
\hline Traballiaderes de frigerifico & 28 & $4(14,3)$ & $2(7,1)$ & $2(7.1)$ \\
\hline Trabahladeres de aviários & 87 & $5(5.7)$ & $4(4,6)$ & $1(1,2)$ \\
\hline Viculeiros & 31 & $3(9,7)$ & $3(9.7)$ & - \\
\hline Fstadantes de Agrotécnica & 60 & $12(20,0)$ & $6(10.0)$ & $7(11.7)$ \\
\hline Trabaltadores da linpeza pública & 51 & $51(9.8)$ & $4(7.8)$ & $1(2,0)$ \\
\hline Totial & 445 & $76(17.1)$ & $48(10.8)$ & $35(7.9)$ \\
\hline
\end{tabular}

* Individues com anticorpos para um ou os disis sorotipos. 
sexo masculino foram mais positivos, porém sem alcançar significância estatística $(p>0,10)$. De modo semelhante, a freqüencia da rorologia positiva foi maior nos indivíduos com mais anos de estudo - os indivíduos com mais de doze anos de estudo, comparados aos demais. tiveram freqüência maior de anticorpos antilistéria $\left(\mathrm{x}^{2}=4,87 \mathrm{p}<0,05\right)$. A sorologia positiva foi mais freqüente entre aqueles com ocupaçôes especializadas ( $p<0,005)$. A mesma tendência foi observada entre os individuos com renda familiar mais alta, porem, sem alcançar significância estatística.

Os procedentes da região urbana tiveram freqüência maior $(p<0,02)$ de indivíduos positivos. A freqüência de individuos com sorologia positiva foi significantemente maior $(p<0.02)$ entre aqueles com menor grau de contato com animais ou aos seus produtos.

Também na Tabela 2 a distribuição dos grupos raciais e do local da residência foi semelhante entre os indivíduos com sorologia positiva e negativa, de igual modo a idade média não diferiu entre estes dois grupos.

\section{DISCUSSÃO}

A freqüência observada de $17,1 \%$ de indivíduos com anticorpos antilistéria pode ser considerada alta, apesar da existência das reações cruzadas 3 . Ao mesmo tempo o resultado observado evidencia a circulação da L. monocytogenes no Triângulo Mineiro. Este aspecto também reforça a necessidade de investigá-la em pacientes imunodeprimidos com quadro clínico de sepsis e meningoencefalites, especialmente recémnascidos ${ }^{27}$.

Em Uberaba, pelo menos, os indivíduos com características urbanas (procedência, número maior de anos de estudo, ocupação especializada, maior nível de renda e grau menor de contato com animais ou seus produtos primários) têm, de forma

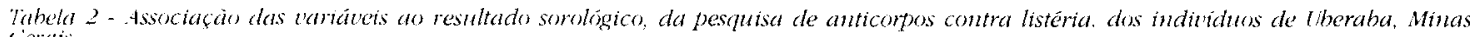
cierais.

\begin{tabular}{|c|c|c|c|c|}
\hline \multirow[b]{2}{*}{ variável } & \multirow[b]{2}{*}{ 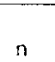 } & \multicolumn{2}{|c|}{ Anticorpos* } & \multirow[b]{2}{*}{ Estatistica } \\
\hline & & $\mathrm{n}$ & $\%$ & \\
\hline \multicolumn{5}{|l|}{ 1. $\operatorname{sex} 0$} \\
\hline masculino & 328 & 61 & 18.6 & \multirow{2}{*}{$\begin{array}{c}\chi^{2}=2,03(\mathrm{~g} .1=1) \\
\mathrm{p}>0,10\end{array}$} \\
\hline f(minino & 117 & 15 & 12.8 & \\
\hline \multicolumn{5}{|c|}{ 2. Idade média (anos) \pm desvio padrāo } \\
\hline negativos & 369 & \multicolumn{2}{|c|}{$29,92 \pm 13.31$} & \multirow{2}{*}{$\begin{array}{c}\mathrm{t}=0,18(\mathrm{~g} .1=443) \\
\mathrm{p}>0.50\end{array}$} \\
\hline positivos & 76 & 30,22 & 12,75 & \\
\hline \multicolumn{5}{|l|}{ 3. Grupo racial } \\
\hline branco & 235 & 43 & 18,3 & \multirow{2}{*}{$\begin{array}{c}x^{2}=0.52(g .1=1) \\
p>0.40\end{array}$} \\
\hline negro $(+$ mulato $)$ & 210 & 33 & 15,7 & \\
\hline \multicolumn{5}{|l|}{ 4. Procedência } \\
\hline rural & 106 & 10 & 9.4 & \multirow{2}{*}{$\begin{array}{c}\chi^{2}=5.74(\mathrm{~g} \cdot 1=1) \\
p<0,02\end{array}$} \\
\hline urbana & 339 & 66 & 19,5 & \\
\hline \multicolumn{5}{|c|}{ 5. Residência atual (Uberaba) } \\
\hline centro & 363 & 65 & 18,0 & \multirow{2}{*}{$\begin{array}{c}\chi^{2}=0,95(g . l=1) \\
p>0,30\end{array}$} \\
\hline periferia + rural & 82 & 11 & 13,4 & \\
\hline \multicolumn{5}{|l|}{ 6. Anos de estudo } \\
\hline $01-14$ & 146 & 19 & 13.0 & \multirow{4}{*}{$\begin{array}{c}\chi^{2}=5,57(\mathrm{~g} .1=3) \\
p>0,10\end{array}$} \\
\hline $51-18$ & 116 & 19 & 16,4 & \\
\hline $91-111$ & 85 & 14 & 16,5 & \\
\hline$>11$ & 98 & 24 & 24,5 & \\
\hline \multicolumn{5}{|l|}{ 7. Ocupação atual } \\
\hline não-qualificada & 137 & 21 & 15,3 & \multirow{3}{*}{$\begin{array}{c}\chi^{2}=11,48(g .1=2) \\
p<0,005\end{array}$} \\
\hline semi-qualificada & 173 & 20 & 11,6 & \\
\hline qualificada & 135 & 35 & 25,9 & \\
\hline \multicolumn{5}{|c|}{ 8. Renda familiar mensal (salários mínimos) } \\
\hline $11-13$ & 325 & 52 & 16,0 & \multirow{3}{*}{$\begin{array}{c}\chi^{2}=1,22(g \cdot 1 .=2) \\
p>0,50\end{array}$} \\
\hline $4 i-110$ & 60 & 11 & 18,3 & \\
\hline$>10$ & 60 & 13 & 21,7 & \\
\hline \multicolumn{5}{|c|}{ 9. Grau de contato com animais ou produtos } \\
\hline menor & 203 & 44 & 21,7 & \multirow{2}{*}{$\begin{array}{c}\chi^{2}=5.57(\mathrm{~g} .1 .=1) \\
\mathrm{p}<0,02\end{array}$} \\
\hline maior & 242 & 32 & 13,2 & \\
\hline
\end{tabular}

" contra um ou ambos sorotipos. 
Tatares-Neto,J. Oliceira GF, Couto-Jünior A, Andrade J, Hofer E Inquérito soro-epidemiológico antilistéria em Uberaba. MG. Revista da Suciedade Brasileira de Medicina Tropical 29:41-45, jan-fer, 1996.

aparentemente paradoxal, freqüência maior de anticorpos antilisteria.

Porém, nos paises desenvolvidos tem-se observado o isolamento da L. monocytogenes em alimentos inclustrializados ${ }^{14}$. Esta informaçào e os nossos resultados evidenciam a importância da listeriose como possível problema de saúcle das regiòes urbanas - onde é crescente o hábito dos habitantes, das cidades maiores, ingerirem alimentos industrializados de origem animal, notadamente as pessoas mais jovens.

Neste sentido, as pessoas do grupo I $6 \mathrm{com}$ número menor de individuos com atividades ocupacionais vinculadas ao contato com animais ou aos seus produtos) tiveram freqüência maior $(25,0 \%)$ de sorologia positiva, do que os do grupo II $(11,3 \%)$. Pertencem a este último grupo os alunos da Escola Agrotécnica e que têm nível sócio-econômico alto, superior ao dos estudantes de Medicina (grupo I) - ambos os grupos de alunos com idades médias semelhantes. A diferença entre eles foi observada no grau de contato com animais ou seus produtos, em $78,3 \%(\mathrm{n}=47)$ dos alunos de Agrotécnica o grau de contato foi considerado maior. sendo observado em $25,0 \%(\mathrm{n}=10)$ dos alunos de Medicina. Apesar desta diferença, as freqüencias da sorologia positiva antilistéria, dos dois grupos de alunos, foram semelhantes $(p>0,80)$. Vale ressaltar, enquanto $45,0 \% \quad(n=18)$ dos alunos de Medicina eram do sexo feminino, somente duas $(3,3 \%)$ mulheres estudavam Agrotécnica. Mesmo assim, as diferenças entre os estudantes de Medicina e Agrotécnica parecem indicar que a semelhança da soro-positividade é mais decorrete das influências do ambiente urbano.

Esta frequência alta de indivíduos com anticorpos antilistéria, em ocupaçoes sem risco aparente, com características mais urbanas. justifica estudos de incidência e de prevalência em outras regioes brasileiras. En estudos longitudinais os fatores de risco poderiam ser adequadamente esclarecidos. Entre eles, os produtos de origem animal que oferecem risco maior consumidos nas cidades, os quais, independentemente, merecem a atença dos órgâos de vigilância sanitária.

\section{SUMMARY}

From a total of 445 inditiduals, $17.1 \% \mathrm{bad}$ antibuties against $\mathrm{L}$. monocytogenes detected by the agglutination tube test. They were separated in seren groups: bloods donnors $(n=50)$. Hospital visitors $(n=40)$, frigorific workers $(n=28)$, aliculture uonkers $(n=87)$, berdsman $(n=31)$. agriculture students $(n=60)$ and street-sweepers $(n=51) . \quad$ L1/2a serotype was predominant. Individuals from urban areas $(19.5 \%)$ and those who bad less contact with animals (21.7\%) had significantly positice serology uben compared with individuals from rual areas $(9.4 \%)$ and those ubo bad close contact with animals $(13.2 \%)$. The overall picture is indiriduals of more specialized occupations bad more fiequently (25.9\%) anti listeria antibodies similat to the results observed in dereloped conntries where listeriosis is a public bealth problem in urban areas.

Key-uords: Antilisteria antibodies. Surey. Listeria monocytogenes. Seroepidemiologgr.

\section{REFERÊNCIAS BIBLIOGRÁFICAS}

1. Acha PN, Szyfres B. Listeriosis. In: Acha PN, Szyfres B (eds) Zoonosis y enfermedades transmisibles comunes al hombre y a los animales. Orgunizacion Panamericana de la Salud, Publicacion cientifica $\mathrm{n}^{\circ}$ 503, Washington, p. 121-127. 1989.

2. Farber JM, Losos JZ. Listeria monucytugenes: a foodborne pathogen. Canadian Medical Association Journal 138:413-418, 1988.

3. Gray ML, Killinger AH. Listeria monocytogenes and listeric infections. Bacteriological Reviews 30:309-382, 1966.

4. Hofer E. Contribuição ao estudo epidemiológico da ocorrência de portadores de Listeria monocytogenes entre operários de matadouro e indivíduos com distúrbios entéricos. Tese de livre docência da Universidade Federal Rural do Rio de Janeiro, Rio de Janeiro, RJ, 1974.

5. Kouba $V$. Infecciones comunes a los animales y al hombre In: Kouba $\mathrm{V}$ (ed) Epizootiologia general. Editora Pucblo y Educacion, Madrid, p. 321-349, 1987.

6. Santa Rosa CA. Listeriose. In: Veronesi R (ed) Doenças infecciosas e parasitárias, Guanabara Koogan, Rio de Janeiro, p. 487-489, 1982.

7. Schaffner A. Listeria monocyogenes. In: Braude I, Davis CE, Fierer J (eds) Infectious diseases and medical micribiology, WB Saunders. Philadelphia, p. 263-266, 1986.

8. Schlech WF, Lavigne PM, Bertolussi RA, Allen AC, Haldene EV, Worth AJ, Hightower AW, Johnson SE, 
Tavares-Neto J, Oliveira GF, Couto-Júnior A, Andrade J, Hofer E. Inquérito soro-epidemiológico antilistéria em Uberaba, MG. Revista da Sociedade Brasileira de Medicina Tropical 29:41-45, jan-fev, 1996.

King SH, Nichols ES, Broome CV. Epidemic listeriosis-evidence for transmission by food. The New England Journal Medicine 308:203-206, 1983 .
9. Seeliger HPR. Modern taxonomy of the Listeria group relationship to its pathogenicity. Clinical Investigation Medicine 7:217-221, 1984. 